\title{
Pro-inflammatory cytokines and bone fractures in CKD patients. An exploratory single centre study
}

\author{
Vincenzo Panuccio ${ }^{1,2}$, Giuseppe Enia ${ }^{1,2^{*}}$, Rocco Tripepi ${ }^{2}$, Roberta Aliotta ${ }^{1,2}$, Francesca Mallamaci ${ }^{1,2}$, \\ Giovanni Tripepi ${ }^{2}$ and Carmine Zoccali, ${ }^{1,2}$
}

\begin{abstract}
Background: Pro-inflammatory cytokines play a key role in bone remodeling. Inflammation is highly prevalent in CKD-5D patients, but the relationship between pro-inflammatory cytokines and fractures in CKD-5D patients is unclear. We studied the relationship between inflammatory cytokines and incident bone fractures in a cohort of CKD-5D patients.

Methods: In 100 CKD-5D patients (66 on HD, 34 on CAPD; males:63, females:37; mean age: 61 \pm 15 ; median dialysis vintage: 43 months) belonging to a single renal Unit, we measured at enrolment bone metabolic parameters (intact PTH, bone and total alkaline phosphatase, calcium, phosphate) and inflammatory cytokines (TNF-a, IL-6, CRP). Patients were followed-up until the first non traumatic fracture.

Results: During follow-up (median: 74 months; range 0.5 -84.0) 18 patients experienced fractures. On categorical analysis these patients compared to those without fractures had significantly higher intact PTH (median: $319 \mathrm{pg} / \mathrm{ml}$ IQ range: $95-741$ vs $135 \mathrm{pg} / \mathrm{ml}$ IQ: 53-346; $\mathrm{p}=0.04$ ) and TNF-a levels (median: $12 \mathrm{pg} / \mathrm{ml}$ IQ: 6.4-13.4 vs $7.8 \mathrm{pg} / \mathrm{ml}$ IQ: 4.6-11; $p=0.02$ ). Both TNF-a (HR for $5 \mathrm{pg} / \mathrm{ml}$ increase in TNF-a: 1.62 95\% Cl: 1.05-2.50; $p=0.03$ ) and intact PTH (HR for $100 \mathrm{pg} / \mathrm{ml}$ increase in PTH: 1.15 95\% Cl: 1.04-1.27; $p=0.005$ ) predicted bone fractures on univariate Cox's regression analysis. In restricted (bivariate) models adjusting for previous fractures, age, sex and other risk factors both PTH and TNF-a maintained an independent association with incident fractures.

Conclusions: In our bivariate analyses TNF-a was significantly associated with incident fractures. Analyses in larger cohorts and with adequate number of events are needed to firmly establish the TNF a -fracture link emerged in the present study.
\end{abstract}

Keywords: Bone fractures, CKD, Dialysis, Hyperparathyroidism, TNF-alpha, Inflammation

\section{Background}

Bone mineral disorders are pervasive in patients with kidney failure on dialysis (CKD stage 5D) and the risk for bone fractures is quadrupled in this population $[1,2]$. Deranged parathyroid function is currently considered as the fundamental alteration responsible for bone disease in CKD [3]. Past exposure to steroids applied to treat immunological renal diseases or administered in previous kidney transplants represents an additional major factor in the pathogenesis of bone fractures in these patients

\footnotetext{
* Correspondence: eniag@libero.it

'Nephrology, Dialysis, Hypertension and Renal Transplantation Unit Azienda Ospedaliera, Via vallone Petrara, 89124, Reggio Calabria, Italy

${ }^{2}$ CNR-IBIM Clinical Epidemiology and Physiopathology of Renal Diseases and Hypertension, Via vallone Petrara, 89124, Reggio Calabria, Italy
}

[1]. Apart from parathyroid hormone (PTH) and other major hormonal regulators of bone metabolism, during the last two decades pro-inflammatory cytokines have fully emerged as major players in bone remodeling [4]. In particular, Tumor Necrosis Factor Alpha (TNF- $\alpha$ ) a cytokine endowed with a large repertoire of biological effects is one of the most powerful inducers of the receptor activator of NF-kB ligand (RANKL), i.e. a key trigger of osteoclast activation and bone resorption [4-7]. High cytokines levels may contribute to increase the risk of osteoporosis and bone fractures in chronic inflammatory disease including COPD [8] and inflammatory bowel disease [9], and the relevance of RANKL pathway in bone health is indicated by the efficacy of drugs impinging upon RANKL in the treatment of osteoporosis in elderly

\section{Ciomed Central}


women [10], including patients in CKD stage 2-4 [11]. Inflammation is a feature of advanced CKD [12-15], but the relationship between pro-inflammatory cytokines and fractures in CKD-5D patients is still unclear. To explore the hypothesis that inflammation may contribute to the high risk of bone fracture in CKD we tested the relationship between inflammatory makers and other bone metabolic parameters with incident bone fractures in a cohort of stable CKD-5D patients without inter-current clinical infectious processes.

\section{Methods}

\section{Study population}

The study protocol was approved by the Ethics Committee of the Azienda Ospedaliera "Bianchi-MelacrinoMorelli" di Reggio Calabria. All patients provided informed consent.

All prevalent patients in January 1995 and incident patients in 1996-1997 [66 on haemodialysis (HD) and 34 on continuous ambulatory peritoneal dialysis (CAPD), 63 males and 37 females] belonging to a single renal Unit, who had been on regular dialysis treatment (RDT) for at least 6 months and without inter-current clinical problems requiring hospitalization were recruited for the study. Patients mean age was $61 \pm 15$ years and the median duration of dialysis treatment was 43 months (interquartile range 18-99 months). Further clinical details about the study population are given in Table 1. Hemodialysis patients were being treated thrice weekly with standard bicarbonate dialysis $\left(\mathrm{Na} 138, \mathrm{HCO}_{3} 35\right.$, $\mathrm{K} 1.5, \mathrm{Ca} 1.25, \mathrm{Mg} 0.75 \mathrm{mmol} / \mathrm{L}$ ) and $1.1-1.7 \mathrm{~m}^{2}$ dialysers (89\% cuprophan, $11 \%$ semi-synthetic membranes). The average fractional urea clearance $(\mathrm{Kt} / \mathrm{V})$ in these patients was $1.28 \pm 0.31$. Dialysis fluid was produced by a reverse osmosis system and Aluminium never exceeded $5 \mu \mathrm{g} / \mathrm{L}$ which is well below the safety limit recommended by the European Council. Patients on CAPD were all on 4 exchanges/day schedule with standard dialysis bags containing $1.75 \mathrm{mmol} / \mathrm{L}$ calcium. The average weekly Kt/V in these patients was $1.67 \pm 0.30$. Sixteen patients were diabetics and 48 were habitual smokers. Forty-nine patients were on treatment with erythropoietin and 60 were taking various anti-hypertensive drugs (42 on mono-therapy with ACE inhibitors, calcium channel blockers or beta blockers and the remaining 18 on double or triple therapy with various combinations of these drugs). Eighteen patients out of 60 on antihypertensive therapy were on treatment with beta blockers (alone or in combination with other drugs). Eighty-six patients were assuming calcium chelating agents (either calcium carbonate or calcium acetate). Forty-seven patients were being treated with calcitriol. None of patients who took part in the study had undergone parathyroidectomy.
Table 1 Main demographic, clinical and biochemical data of patients

\begin{tabular}{|c|c|c|c|}
\hline & $\begin{array}{c}\text { With } \\
\text { Fractures } \\
\text { (n.18) }\end{array}$ & $\begin{array}{c}\text { Without } \\
\text { Fractures } \\
\text { (n.82) }\end{array}$ & $p$ \\
\hline Age (years) & $61 \pm 13$ & $61 \pm 15$ & 0.91 \\
\hline Male Sex (\%) & 61 & 63 & 0.86 \\
\hline Duration of RDT (months) & $35(14-75)$ & $44(18-101)$ & 0.47 \\
\hline $\mathrm{BMI}\left(\mathrm{Kg} / \mathrm{m}^{2}\right)$ & $26.8 \pm 4.8$ & $25.1 \pm 4.4$ & 0.18 \\
\hline Height (cm) & $159 \pm 10$ & $161 \pm 10$ & 0.48 \\
\hline Smokers (\%) & 50 & 48 & 0.85 \\
\hline Diabetics (\%) & 17 & 16 & 0.93 \\
\hline Treated with Beta blockers (\%) & 6 & 21 & 0.13 \\
\hline Treated with Calcitriol (\%) & 39 & 49 & 0.45 \\
\hline $\begin{array}{l}\text { Treated with Ca-carbonate } \\
\text { or Ca- acetate (\%) }\end{array}$ & 83 & 87 & 0.72 \\
\hline Treated with ESAs (\%) & 39 & 51 & 0.34 \\
\hline Hemodialysis/CAPD (n.) & $15 / 3$ & $51 / 31$ & 0.09 \\
\hline $\begin{array}{l}\text { History of previous } \\
\text { fractures (\%) }\end{array}$ & 24 & 4 & 0.009 \\
\hline $\begin{array}{l}\text { History of renal } \\
\text { transplantation (\%) }\end{array}$ & 6 & 10 & 0.56 \\
\hline Haemoglobin (g/dL) & $9.8 \pm 2.6$ & $10.5 \pm 1.8$ & 0.27 \\
\hline Serum Albumin (g/dl) & $4.0 \pm 0.7$ & $3.8 \pm 0.6$ & 0.27 \\
\hline Serum Calcium (mmol/L) & $4.5 \pm 0.6$ & $4.5 \pm 0.6$ & 0.73 \\
\hline Serum Phosphate (mg/dl) & $6.0 \pm 1.4$ & $6.0 \pm 1.6$ & 0.92 \\
\hline Intact PTH (pg/mL) & $319(95-741)$ & $135(53-346)$ & 0.04 \\
\hline intact PTH $<100 \mathrm{pg} / \mathrm{ml}(\%)$ & 28 & 46 & 0.15 \\
\hline intact PTH > 800 pg/ml (\%) & 22 & 6 & 0.03 \\
\hline $\begin{array}{l}\text { Bone Alkaline phosphatase } \\
(\mu \mathrm{g} / \mathrm{L})\end{array}$ & $15.0(6.4-21.2)$ & $12.7(7.9-22.9)$ & 0.89 \\
\hline $\begin{array}{l}\text { Total Alkaline phospatase } \\
(\mathrm{UI} / \mathrm{L})\end{array}$ & $67(58-98)$ & $69(51-86)$ & 0.88 \\
\hline IL-6 (pg/mL) & $6.1(3.2-8.0)$ & $7.2(3.3-11.0)$ & 0.50 \\
\hline CRP (mg/L) & $11.1(3.5-28.2)$ & $8.9(3.4-19.1)$ & 0.59 \\
\hline TNF-a (pg/mL) & $12.0(6.4-13.4)$ & $7.8(4.6-11.0)$ & 0.02 \\
\hline
\end{tabular}

Data are expressed as mean $\pm \mathrm{SD}$, median and inter-quartile range or as percent frequency, as appropriate. Patients are divided into 2 groups on the basis incident fractures occurrence. $P$ tests the differences among the groups. Significant differences between groups are indicated in bold. Intact PTH thresholds of $<100$ and $>800 \mathrm{pg} / \mathrm{ml}$ identify low and high bone turn-over, respectively [18]. ESAs = erythropoiesis-stimulating-agents.

\section{Laboratory methods}

Fasting blood sampling was performed during a midweek non-dialysis day for HD patients. Samples were stored in prechilled vacutainers containing edetic acid, placed immediately on ice, and centrifuged within $30 \mathrm{~min}$ at $4{ }^{\circ} \mathrm{C}$; plasma was stored at $-80{ }^{\circ} \mathrm{C}$ until required. Serum calcium, serum phosphate, haemoglobin and alkaline phosphatase measurements were made using standard methods in the routine clinical laboratory. Intact PTH molecule measurement was made by a specific immuno- 

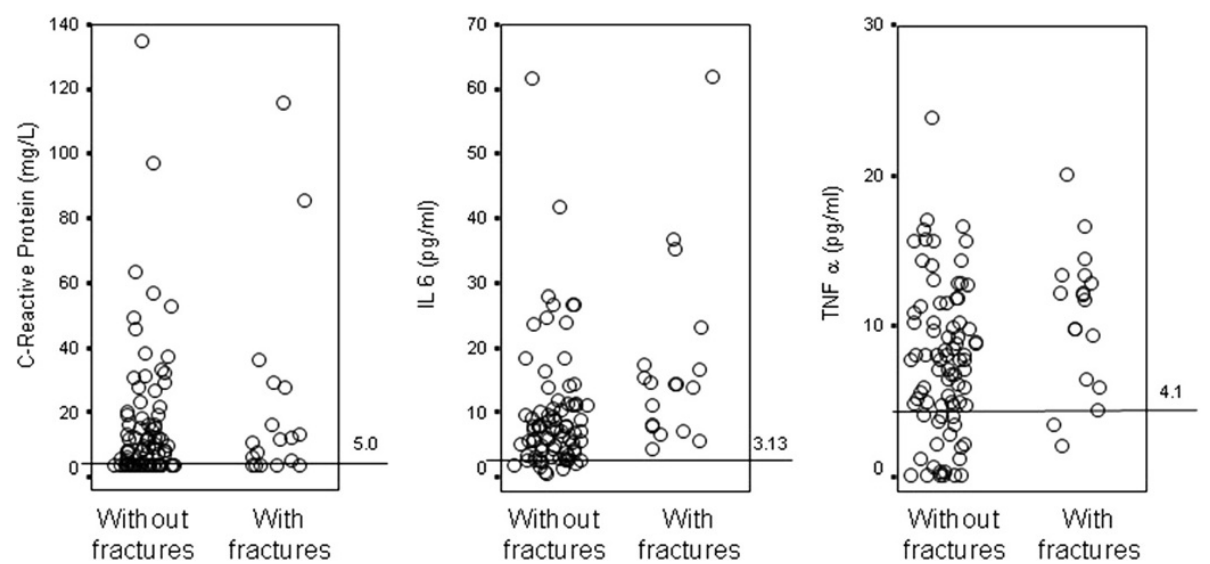

Figure 1 Distribution of CRP, IL-6 and TNF-a levels. Lines indicate the upper limit of the normal range.

radiometric assay (Scantibody Laboratory Inc, Santee, CA, USA). Bone skeletal phosphatase was measured by an immunoradiometric method (Tandem-Ostase, Hybritech, USA).

C-Reactive Protein was determined by a standard immunonephelometric method (Behring, Scoppito, L'Aquila, Italy) with normal values $<5 \mathrm{mg} / \mathrm{L}$. ELISA by commercially available kits (R\&D Systems Inc, Minneapolis, USA) was used to determine IL-6 (normal values $<3.13 \mathrm{pg} / \mathrm{ml}$; coefficient of variation: intra-assay $=2.6 \%$, inter-assay $=4.5 \%$ ) and TNF- $\alpha$ (normal values $<4.1 \mathrm{pg} / \mathrm{ml}$; coefficient of variation: intra-assay $=4.7 \%$, inter-assay $=5.8 \%)[16]$.

\section{Follow-up study}

Fractures were defined as non-traumatic events documented by imaging techniques (i.e. radiography, computerized axial tomography or nuclear magnetic resonance). We considered fractures of the femoral neck (intertrochanteric, or subtrochanteric fractures), fractures of other parts of the femur (condyle, supracondylar, and epiphysis), vertebral fractures and fractures interesting other skeletal segments. Vertebral fractures were diagnosed using a semi-quantitative approach [17].

After enrollment patients were followed-up until the first fracture, those who died or underwent transplant or were free of fractures at the end of study were censored no patient was lost to follow-up. Median follow-up was 74 months (range 0.5-84.0 months).

\section{Statistical analysis}

Data are reported as mean $\pm \mathrm{SD}$, median and inter-quartile range or as prevalence rate and differences between groups were analyzed by the T-test, the Mann-Whitney test or the Chi-Squared Test, as appropriate. The

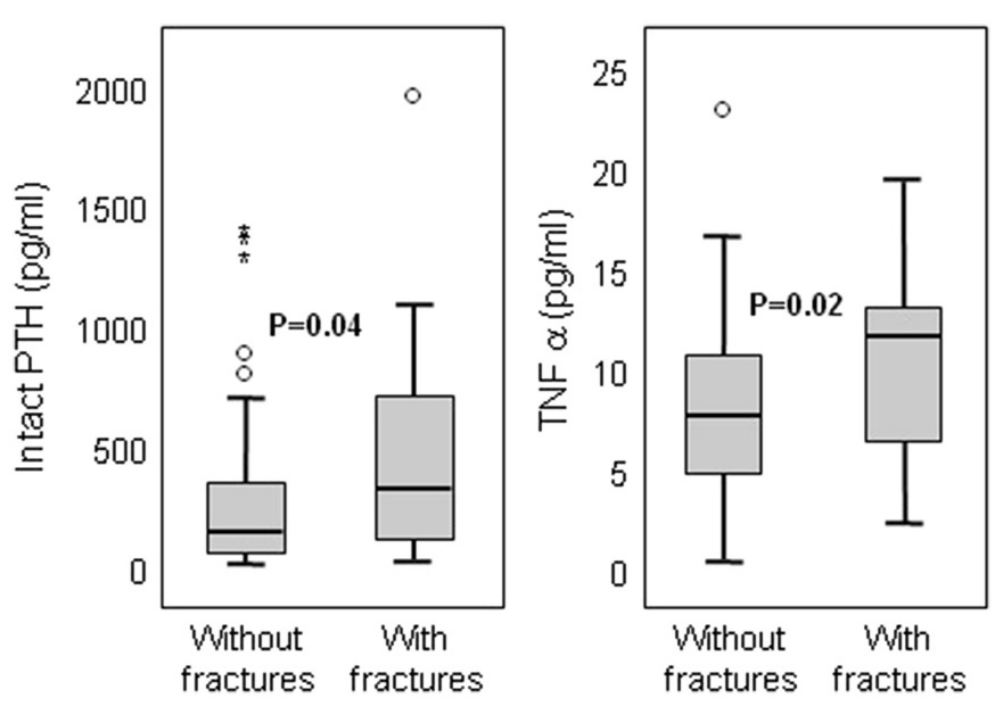

Figure 2 Serum intact PTH and TNF-a levels (median and interquartile range) in patients with and without incident fractures. 


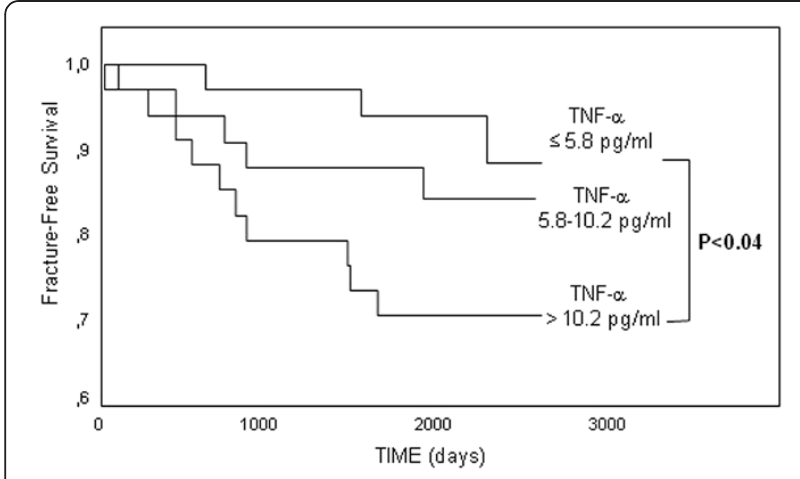

Figure 3 Fracture-free survival according to TNF tertiles. KaplanMeyer curves and log-rank test.

association between incident fractures with serum PTH, total and bone alkaline phosphatase, calcium, phosphate, TNF- $\alpha$, CRP, Il- 6 and others potential risk factors was preliminarily analyzed by dividing patients into two groups (patients with and without incident fractures) and by testing the differences between them. To identify patients with low and high bone turn-over we used intact PTH thresholds suggested by European Best Practice Group [18]. The predictive value of biomarkers of inflammation, mineral and bone disorder and other potential risk factors was analyzed by univariate Cox's proportional hazards method. In the Cox's analysis the proportional hazard assumption was tested by the analysis of Schoenfeld residuals and no violation was found. Due to the small number of fractures to assess the idependent link between TNF- $\alpha$ and fractures we entered this risk factor in(restricted) bivariate models considering other risk factors one at a time. Furthermore, we computed a risk score [19] in each patient by summing up the individual profile of 5 risk factors for fractures, each dichotomized as following : sex female $=1$ male $=0$, previous fractures $=1$ no previous fractures $=0$, previous transplants $=1$ no previous transplants $=0$, intact $\mathrm{PTH}>$ median value $=1$ intact $\mathrm{PTH}<$ median value $=0$,

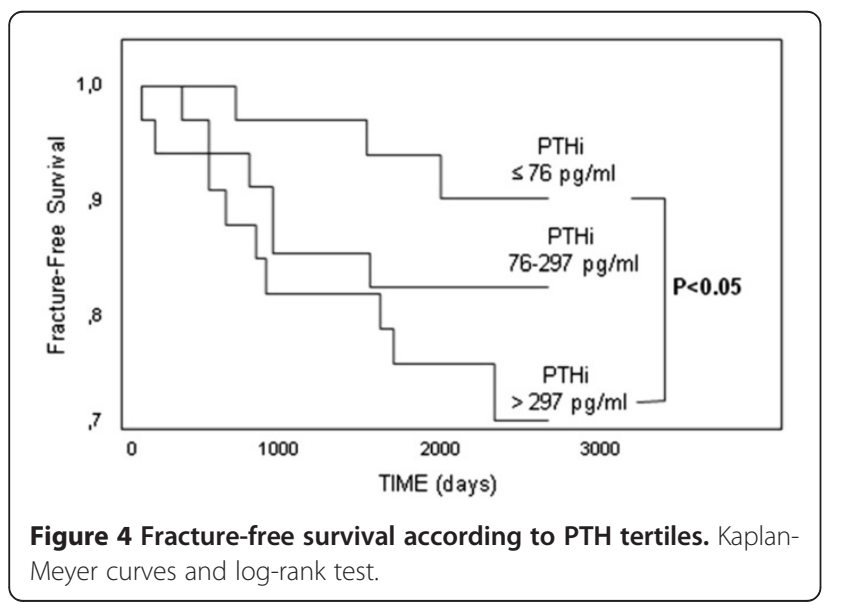

age $>$ median value $=1$ age $<$ median value $=0$. The potential confounding effect of this score, reflecting the combined effect of major risk factors for fractures, was then tested in an additional bivariate model.

Data are expressed as hazard ratio (HR) and 95\% confidence interval (CI). All calculations were done using a standard statistical package (SPSS for Windows).

\section{Results}

C-Reactive Protein, IL- 6 a and TNF- $\alpha$ levels above the upper limit of the normal range were observed in $65 \%$, $77 \%$ and $78 \%$ of patients, respectively (Figure 1). During the follow-up period (median 74 months; range: 0.5-84.0 months) 18 patients had incident fractures (vertebral $=10$; pelvic $=4$; femoral neck $=1$; humerus $=1$; $\operatorname{costal}=1$; clavicle $=1$ ). Patients with incident fractures had higher levels of serum intact PTH, and TNF- $\alpha$ when compared to those without these complications (Table 1, Figure 2) while CRP and IL-6 levels were similar in the two groups. The proportion of patients with PTH in the range denoting low bone turn-over $(<100 \mathrm{pg} / \mathrm{ml})$ according to current guidelines [18] did not differ, while the proportion of those with high turn-over $(>800 \mathrm{pg} / \mathrm{ml})$ was higher among patients with incident fractures (Table 1). The proportion of patients who had suffered from a previous fracture was markedly higher in patients who had incident fractures (Table 1).

On Kaplan-Meyer analysis fracture-free survival was longer in patients with TNF- $\alpha$ in the lower tertile as compared to those with levels in the upper tertile (Figure 3). Similarly PTH levels in the lower tertile were associated to a longer fracture-free survival (Figure 4). On univariate Cox analysis the association between TNF- $\alpha$ with incident fractures was significant ( $\mathrm{HR}$ for $5 \mathrm{pg} / \mathrm{ml}$ increase in TNF- $\alpha$ : 1.62 95\% CI: 1.05-2.50; $\mathrm{p}=0.03$ ) as it was the association between fractures and PTH (HR for $100 \mathrm{pg} / \mathrm{ml}$

Table 2 Crude and adjusted relative risk of plasma TNF-a for incident fractures

\begin{tabular}{|c|c|}
\hline & $\begin{array}{l}\text { Hazard ratio and } 95 \% \mathrm{Cl} \text { associated } \\
\text { to } 5 \mathrm{pg} / \mathrm{mL} \text { increase in plasma } \\
\text { TNF- } \mathrm{a} \text { for incident fractures }\end{array}$ \\
\hline Crude & $1.62(1.05-2.50), P=0.03$ \\
\hline
\end{tabular}

Adjusted for:

$\begin{array}{ll}\text { Age } & 1.64(1.06-2.56), P=0.03 \\ \text { Intact PTH } & 1.55(1.03-2.35), P=0.04 \\ \text { Sex } & 1.64(1.06-2.54), P=0.03 \\ \text { Previous fractures } & 1.61(1.01-2.57), P=0.04 \\ \text { Previous transplants } & 1.59(1.05-2.40), P=0.03 \\ \text { Risk Score } & 1.60(1.04-2.45), P=0.03\end{array}$

Plasma TNF-a data were adjusted in bivariate Cox models including TNF- $a$ and each risk factor listed. The latter factors were used to compute the risk score (see methods). 
increase in PTH: 1.15 95\% CI: 1.04-1.27; p=0.005). History of previous fractures increased by four-fold the risk of incident fractures (HR 4.47 95\% CI: 1.46-13.7; $\mathrm{p}=0.009$ ). CRP and IL-6, total and bone alkaline phosphatase, serum calcium and phosphate largely failed to predict fractures.

In reduced bivariate models the association of TNF- $\alpha$ with fractures proved to be independent of intact PTH, age, sex, history of previous transplants and previous fractures and of the risk score composed by the same risk factors (Table 2).

\section{Discussion}

Our exploratory observations, confirming the central role of PTH, have shown that TNF- $\alpha$ is associated with incident fractures in CKD -5D population. These findings generate the hypothesis that systemic inflammation might contribute to increase the bone fracture risk in these patients.

In the last two decades the biology of osteoclast activation has been intensively investigated and the RANKL/ RANK pathway emerged as a fundamental modulator of osteoclastogenesis [4]. Inflammatory cytokines are well established potent activators of the RANKL/RANK pathway [4-7] and play a direct role in osteoclastogenesis in post-menopausal women [20]. Furthermore, recent longitudinal studies [21-23] coherently suggest that high cytokines levels may contribute to bone loss and fractures in elderly women and men.

We once again confirm that inflammation is pervasive in CKD-5D patients [12-15]. Indeed, CRP levels were above the upper limit of the normal in as much as $65 \%$ of patients at time of enrolment. In the present study TNF- $\alpha$ was substantially increased, being above the upper normal range in $78 \%$ of patients, a figure close to that of other biomarkers of inflammation, but it was the only cytokine linked to the fracture risk. The finding is consistent with studies showing that among the cytokines, TNF $\alpha$ is the most powerful stimulator of osteoclastogenesis [4-7].

Our study has limitations. First, we measured TNF- $\alpha$ and other cytokines only once. Since the precision of the estimate of the usual level of inflammation biomarkers increases with repeated measures, the link between TNF- $\alpha$ and bone fractures might be even stronger than emerged in the present analysis. On the other hand, because of the low number of events, the possibility that the TNF- $\alpha$-fractures link may merely represent a false positive finding cannot be dismissed. We controlled for confounding by adopting a parsimonious approach based on bivariate Cox models and a composite risk score [19], and found that the relationship between TNF- $\alpha$ and the risk of incident fractures proved to be independent of PTH, as well as of major confounders like age, sex, previous fractures and previous kidney transplants. Notwithstanding these adjustments failed to materially change the risk of fractures associated with high TNF- $\alpha$, we cannot exclude residual confounding. A second obvious limitation is that we did not measure the full set of hormones controlling mineral balance including 25 hydroxy vitamin $\mathrm{D}$ and 1,25 hydroxy vitamin $\mathrm{D}$ and FGF23. Moreover we have not evaluated serum magnesium levels and did not study the relationships between inflammation and vascular calcifications. Finally, our data collected in a single Renal Unit cannot be generalized to the greater HD population. Due to these limitations our data are merely hypothesis generating. The relationship between fractures and inflammatory cytokines in CKD-5D patients needs to be confirmed in larger cohorts gathering a substantial higher number of bone events. The issue is of relevance because bone fractures in CKD-5D patients not only engender disabling orthopaedic problems but are also associated to increased mortality [24].

\section{Conclusions}

In conclusion, our observations generate the hypothesis that TNF $\alpha$ plays a role in the increased risk of bone fractures in CKD-5D patients. Analyses in larger cohorts and with adequate number of events are needed to firmly establish the TNF $\alpha$-fracture link emerged in the present study.

\section{Competing interests}

No conflict of interest is related to this manuscript.

\section{Authors' contribution}

All Authors have made substantial contributions to conception and design, analysis and interpretation of data and have given final approval of the version to be published. RT and GT performed the statistical analysis. CZ and GE have been involved in drafting the manuscript. All authors read and approved the final manuscript.

\section{Acknowledgements}

The contribution of the Cardiovascular Risk Extended Evaluation in Dialysis (CREED) patients investigators is acknowledged.

Received: 19 April 2012 Accepted: 23 September 2012

Published: 9 October 2012

\section{References}

1. Jadoul M, Albert JM, Akiba T, Akizawa T, Arab L, Bragg-Gresham JL, Mason N, Prutz KG, Young EW, Pisoni RL: Incidence and risk factors for hip or other bone fractures among hemodialysis patients in the Dialysis Outcomes and Practice Patterns Study. Kidney Int 2006, 70:1358-1366.

2. Jadoul M: Towards the prevention of bone fractures in dialysed patients? Nephrol Dial Transplant 2007, 22:3377-3380.

3. Hruska KA, Teitelbaum SL: Renal osteodystrophy. N Engl J Med 1995, 333:166-174.

4. Rachner TD, Khosla S, Hofbauer C: Osteoporosis: now and the future. Lancet 2011, 377:1276-1287.

5. Hardy $\mathrm{R}$, Cooper MS: Bone loss in inflammatory disorders. $J$ Endocrinol 2009, 201:309-320.

6. Kimble RB, Bain S, Pacifici R: The functional block of TNF but not of IL-6 prevents bone loss in ovariectomized mice. J Bone Miner Res 1997, 12:935-941.

7. Hofbauer LC, Lacey DL, Dunstan CR, Spelsberg TC, Riggs BL, Khosla S: Interleukin-1beta and tumor necrosis factor-alpha, but not interleukin-6, 
stimulate osteoprotegerinligand gene expression in human osteoblastic cells. Bone 1999, 25:255-259.

8. Lehouck A, Boonen S, Decramer M, Joanssens W: COPD, bone metabolism and osteoporosis. Chest 2011, 139:648-657.

9. Ali T, Lam D, Bronze MS, Humphrey MB: Osteoporosis in inflammartory bowel disease. Am J Med 2009, 122:599-604.

10. Cummings SR, San Martin J, MCClung MR, et al: for the FREEDOM Trial. Denosumab for prevention of fractures in postmenopausal women with osteoporosis. N Engl J Med 2009, 361:756-765.

11. Jamal SA, Ljunggren O, Stehman-Breen C, Cummings SR, McClung MR, Goemaere S, Ebeling PR, Franek E, Yang YC, Egbuna Ol, Boonen S, Miller PD: Effects of denosumab on fracture and bone mineral density by level of kidney function. J Bone Miner Res 2011, 26:1829-1835.

12. Stenvinkel $P$, Wanner C, Metzger T, Heimburger O, Mallamaci F, Tripepi G, Malatino L, Zoccali C: Inflammation and outcome in end-stage renal failure: does female gender constitute a survival advantage? Kidney Int 2002, 62:1791-1798.

13. Paniagua $R$, Frias $Y$, de Ventura MJ, Rodriguez E, Hurtado ME, Alcantara $G$, Vazquez R, Ortiz R, Salcedo M, Rios ME, Kaji J, Amato D: C-reactive protein and anti-Chlamydia pneumoniae antibodies as risk factors of cardiovascular death in incident patients on peritoneal dialysis. Perit Dial Int 2003, 23:132-137.

14. Herzig KA, Purdie DM, Chang W, Brown AM, Hawley CM, Campbell SB, Sturtevant JM, Isbel NM, Nicol DL, Johnson DW: Is C-reactive protein a useful predictor of outcome in peritoneal dialysis patients? J Am Soc Nephrol 2001, 12:814-821.

15. Meuwese CL, Snaedal S, Halbesma N, Stenvinkel P, Dekker FW, Qureshi AR, Barany P, Heimburger O, Lindholm B, Krediet RT, Boeschoten EW, Carrero JJ: Trimestral variations of C-reactive protein, interleukin- 6 and tumour necrosis factor- $a$ are similarly associated with survival in haemodialysis patients. Nephrol Dial Transplant 2011, 26:1313-1318.

16. Ridker PM, Rifai N, Pfeffer M, Sacks F, Lepage S, Braunwald E: Elevation of Tumor Necrosis Factor-a and Increased Risk of Recurrent Coronary Events After Myocardial Infarction. Circulation 2000, 101:2149-2153.

17. Genant HK, Wu CY, Van KuijK C, Nevitt MC: Vertebral Fracture Assessment Using a Semiquantitative Technique. J Bone Miner Res 1993, 8:1137-1148.

18. Goldsmith DJA, Covic A, Fouque D, Locatelli F, Olgaard K, Rodriguez M, Spasovski G, Urena P, Zoccali C, London GM, Vanholder R: Endorsement of the Kidney Disease Improving Global Outcomes (KDIGO) Chronic Kidney Disease-Mineral and Bone Disorder (CKD-MBD) Guidelines: a European Renal Best Practice (ERBP) commentary statement. Nephrol Dial Transplant 2010, 25:3823-3831.

19. Miettinen OS: Stratification by a multivariate confounder score. Am J Epidemiol 1976, 104:609-620.

20. D'Amelio P, Grimaldi A, Di Bella S, Brianza SZ, Cristofaro MA, Tamone C, Giribaldi G, Ulliers D, Pescarmona GP, Isaia G: Estrogen deficiency increases osteoclastogenesis up-regulating T cells activity: a key mechanism in osteoporosis. Bone 2008, 43:92-100.

21. Cauley JA, Danielson ME, Boudreau RM, Forrest KY, Zmuda JM, Pahor M, Tylavsky FA, Cummings SR, Harris TB, Newman AB: for the Health ABC Study. Inflammatory markers and incident fracture risk in older men and women: the Health Aging and Body Composition Study. J Bone Miner Res 2007, 22:1088-1095.

22. Barbour KE, Boudreau R, Danielson ME, Youk AO, Wactawski-Wende J, Greep NC, Lacroix AZ, Jackson RD, Wallace RB, Bauer DC, Allison MA, Cauley JA: Inflammatory markers and the risk of hip fracture: The women's health initiative. J Bone Miner Res 2012, doi:10.1002/jbmr.1559.

23. Ensrud KE, Barbour K, Canales MT, Danielson ME, Boudreau RM, Bauer DC, Lacroix AZ, Ishani A, Jackson RD, Robbins JA, Cauley JA: Renal function and nonvertebral fracture risk in multiethnic women: the Women's Health Initiative (WHI). Osteoporos Int 2012, 23:(3)887-899. Epub 2011 May 28.

24. Mittalhenkle A, Gillen DL, Stehman-Breen C: Increased Risk of Mortality Associated With Hip Fracture in the Dialysis Population. Am J Kidney Dis 2004, 44:672-679.

doi:10.1186/1471-2369-13-134

Cite this article as: Panuccio et al:: Pro-inflammatory cytokines and bone fractures in CKD patients. An exploratory single centre study. BMC Nephrology 2012 13:134.

\section{Submit your next manuscript to BioMed Central and take full advantage of:}

- Convenient online submission

- Thorough peer review

- No space constraints or color figure charges

- Immediate publication on acceptance

- Inclusion in PubMed, CAS, Scopus and Google Scholar

- Research which is freely available for redistribution 